\title{
Indexing the Diffraction Patterns and Investigating the Crystal Structure of Pb-doped Strontium Ferrites
}

\author{
Z. Ullah, S. Atiq ${ }^{*}$, and S. Naseem \\ Centre of Excellence in Solid State Physics, University of the Punjab, Lahore-54590, Pakistan
}

Received 7 August 2012, accepted in final revised form 22 February 2013

\begin{abstract}
Strontium hexaferrites were prepared in powder form by sol-gel auto-ignition technique and $\mathrm{Pb}$ was doped in different concentrations to attain the various compositions $\mathrm{Sr}_{1-\mathrm{x}} \mathrm{Pb}_{\mathrm{x}} \mathrm{Fe}_{12} \mathrm{O}_{19}$ $(x=0.00,0.05,0.10,0.15,0.20)$. Sintering treatment of the samples was made at $800{ }^{\circ} \mathrm{C}$ for the development of stable hexagonal phase. X-ray diffraction analysis of the samples was carried out for the confirmation and determination of crystal structure of the material. Data obtained from X-ray diffraction analysis helped in determining various parameters of the samples like lattice parameters, volume of the unit cell, crystallite size, bulk density of the samples, X-ray density and porosity of the samples.
\end{abstract}

Keywords:Ferrites; Sol-gel method; X-Ray diffraction; Crystal structure.

@ 2013 JSR Publications. ISSN: 2070-0237 (Print); 2070-0245 (Online). All rights reserved. doi: http://dx.doi.org/10.3329/jsr.v5i2.11578 $\quad$ J. Sci. Res. 5 (2), 235-244 (2013)

\section{Introduction}

Strontium hexaferrites are the prominent magnetic materials due to their supreme applications in diversity of fields. Their latest use in recording media and microwave devices provided them distinctive ranking in the list of magnetic materials. Owing to their excellent chemical stability and easy and low cost manufacturing, these are being synthesized by variety of methods [1]. Besides co-precipitation, microemulsion [2] and conventional ceramic methods [3], these ferrites are also being synthesized by sol-gel technique [4]. The spectacular properties of these ferrites can be tuned according to the requirement, with the assistance of fundamental doping process. Doping of some appropriate element in a particular proportion can play a vital role in altering the astonishing properties of the materials. For example, doping of $\mathrm{Pb}$ in $\mathrm{SrFe}_{12} \mathrm{O}_{19}$ lowers its coercivity and remanence due to which general behavior of these ferrites is changed $[1,5]$. This is also true for many other soft ferrites $[6,7]$.

\footnotetext{
*Corresponding author: shahidatiqpasrur@yahoo.com
} 
Crystal structure of the material controls its various properties [8]. Ferrites are classified with respect to their properties as well as crystal structure. Different types of ferrites like spinel, garnet and hexaferrites have different structures, varying from very easy to most complex [9]. Many scientists preceded their research work on investigation of crystal structure of $\mathrm{SrFe}_{12} \mathrm{O}_{19}$ and reported their detailed results. For instance, Fang et al. [10] determined the crystal structure of $\mathrm{SrFe}_{12} \mathrm{O}_{19}$ using density functional theory. The crystallographers have determined that the crystal structure of $\mathrm{SrFe}_{12} \mathrm{O}_{19}$ is hexagonal. Iqbal et al. [11] synthesized $\mathrm{Zr}-\mathrm{Zn}$ doped $\mathrm{SrFe}_{12} \mathrm{O}_{19}$ and determined its lattice parameters, unit cell volume, crystallite size, bulk density, X-ray density and porosity by analyzing diffraction patterns.

To investigate the material properties, it is necessary to know about its structure. Without attaining the knowledge of crystal structure of the materials, it becomes very hard to investigate its properties [8]. In the present paper, X-ray diffraction analysis of the compositions $\mathrm{Sr}_{1-\mathrm{x}} \mathrm{Pb}_{\mathrm{x}} \mathrm{Fe}_{12} \mathrm{O}_{19}(x=0,0.05,0.1,0.15,0.2)$ has been discussed in details. A complete procedure of indexing and calculating various parameters related to this technique are explained in a simple way. This knowledge will provide a way to make a precise analysis of diffraction patterns of the other materials.

\section{Experimental Procedure}

Sol-gel auto-combustion technique was used for the preparation of various compositions of $\mathrm{Pb}$-doped $\mathrm{SrFe}_{12} \mathrm{O}_{19}$. For the preparation of compositions $\mathrm{Sr}_{1-\mathrm{x}} \mathrm{Pb}_{\mathrm{x}} \mathrm{Fe}_{12} \mathrm{O}_{19}(x=0,0.05$, $0.1,0.15,0.2)$, required proportion of the metal nitrates and citric acid were measured with the help of a precise digital balance. All the materials were in powder form. Strontium nitrate (99\%), iron (III) nitrate (98\%), lead (II) nitrate $(99 \%)$ and citric acid $(99.5 \%)$ were dissolved in de-ionized water separately, and then mixed to make a total volume of $50 \mathrm{ml}$. $\mathrm{pH}$-meter measured the $\mathrm{pH}$ of the solution as 2.5 .

The magnetic capsule (stirrer) was put in the solution and beaker was placed on a hotplate. The setup was housed in an ESCO fume hood. Stirring of solution was started and temperature of the hotplate was increased gradually up to $150{ }^{\circ} \mathrm{C}$. The solution was heated and stirred for about 45 minutes, till the gel was formed. As the gel was formed, the temperature of the sample was further increased up to $250^{\circ} \mathrm{C}$. The gel was heated at this temperature for about 30 minutes when its combustion was started. It was allowed to combust normally. The sample took about 30 minutes for its complete combustion. During this interval, various gases were evolved from the beaker. The end product was a homogenous dry powder.

After complete combustion of the sample, the temperature of the hotplate was decreased gradually. Within 10 minutes, the hotplate was switched off and the sample was cooled down in air at room temperature. Although, the material was already in powder form but it became very fine after grinding, using an Agate mortar and pestle. Fine powder was put in the sample bottle. All the compositions were prepared in the same way. The samples were sintered at $800{ }^{\circ} \mathrm{C}$ for two hours in a muffle furnace. The prepared 
samples were analyzed for the crystal structure, using the diffraction pattern, obtained from X-ray diffraction (XRD).

\section{Results and Discussion}

Data obtained from XRD for the first sample $(x=0)$ has been plotted in Fig. 1. The first task is to determine the crystal structure of the sample using this data. It is very tough job to determine the crystal structure of some unknown material, than that of a known one. In a diffraction pattern, the pattern of diffracted lines tells about the crystal structure, the positions of lines have information about the unit cell and the positions of the atoms can be judged by the intensities of the lines [8].

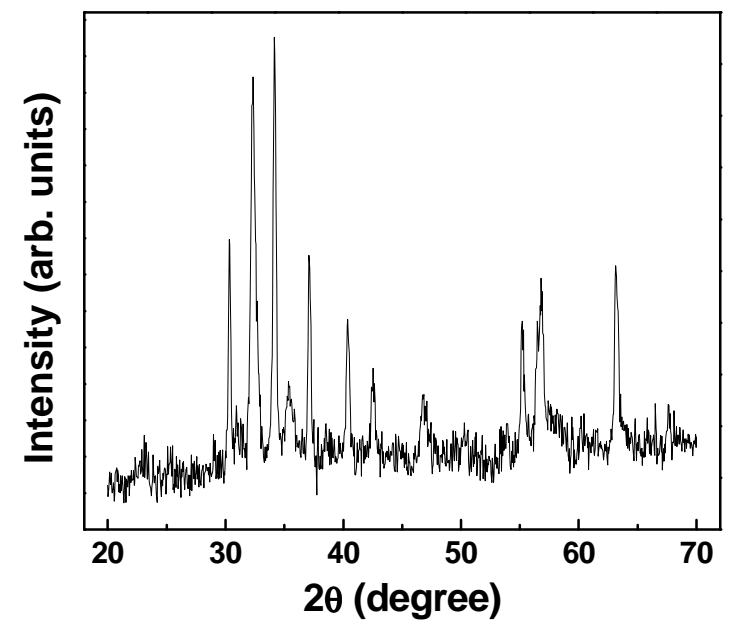

Fig. 1. Plot of data received from X-ray diffractometer.

From the XRD pattern shown in Fig. 1, it is expected that it is the diffraction pattern of hexagonal $\mathrm{SrFe}_{12} \mathrm{O}_{19}$. The first step is to index this pattern that will tell about the crystal system, to which the material is belonged. For this, the values of $\sin ^{2} \theta$ are calculated for all major diffraction lines, as tabulated in Table 1 . These values provide a base to solve the pattern. If there are some diffraction lines due to impurities in material or due to other reasons, then it creates problems and needs extra skills to tackle them.

A relation is developed by combing plane-spacing equation and Bragg's law equation, which determines the Miller indices of some specific crystal system. Suppose, for a cubic system, this expression can be written as [8]:

$$
\frac{\sin ^{2} \theta}{\left(h^{2}+k^{2}+l^{2}\right)}=\frac{\sin ^{2} \theta}{s}=\frac{\lambda^{2}}{4 a^{2}}
$$


Here $\frac{\lambda^{2}}{4 a^{2}}$ is a constant and $s=h^{2}+k^{2}+l^{2}$, which is determined by $\sin ^{2} \theta$ values.

For an unknown material, it has to be found that the values of $\sin ^{2} \theta$ are integral multiple of which $h k l$ values? First, we check the $h k l$ values of a cubic system. If these do not satisfy, then we try for the other systems like tetragonal, hexagonal, etc. one by one. As the pattern under present study is expected to be of hexagonal crystal structure, hence it should obey the modified form of Eq. (1), given as [8]:

$$
\sin ^{2} \theta=A\left(h^{2}+h k+k^{2}\right)+C l^{2}
$$

Here, $A=\frac{\lambda^{2}}{3 a^{2}}$ and $C=\frac{\lambda^{2}}{4 c^{2}}$. The value of ' $A$ ' can be obtained at $h k O(l=0)$. Hence, the permissible values of $\left(h^{2}+h k+k^{2}\right)$ are $1,3,4,7,9$, etc. Therefore, the values of $\sin ^{2} \theta$ in Table 1 , were divided by $1,3,4,7$, etc. to get $h k l$ values for hexagonal system, as shown in Table 2. Lattice parameter ' $a$ ' is calculated for all values of $\sin ^{2} \theta$. There is some order in particular values of ' $a$ ', being integral multiple of each other. Least value from them is the value of ' $a$ ' for 100 plane. Value $a / 2$ is value of ' $a$ ' for 200 plane, and $a / 3$ for 300 plane and so on.

Table 1. Diffraction lines and their corresponding angles taken from diffraction plot.

\begin{tabular}{ccccc}
\hline Line & $2 \theta$ & $\theta$ & $\operatorname{Sin} \theta$ & $\sin ^{2} \theta$ \\
\hline 1 & 23.10 & 11.55 & 0.2002 & 0.0401 \\
2 & 25.5 & 12.75 & 0.2207 & 0.0487 \\
3 & 29.00 & 14.50 & 0.2504 & 0.0627 \\
4 & 30.30 & 15.15 & 0.2613 & 0.0683 \\
5 & 30.90 & 15.45 & 0.2664 & 0.0710 \\
6 & 32.33 & 16.165 & 0.2784 & 0.0775 \\
7 & 34.15 & 17.075 & 0.2936 & 0.0862 \\
8 & 35.20 & 17.60 & 0.3024 & 0.0914 \\
9 & 35.41 & 17.705 & 0.3041 & 0.0925 \\
10 & 36.50 & 18.25 & 0.3132 & 0.0981 \\
11 & 37.10 & 18.55 & 0.3181 & 0.1012 \\
12 & 40.40 & 20.20 & 0.3453 & 0.1192 \\
13 & 42.55 & 21.275 & 0.3628 & 0.1317 \\
14 & 46.85 & 23.425 & 0.3975 & 0.1580 \\
15 & 50.30 & 25.15 & 0.4250 & 0.1806 \\
16 & 53.95 & 26.975 & 0.4536 & 0.2058 \\
17 & 55.20 & 27.60 & 0.4633 & 0.2146 \\
18 & 56.80 & 28.40 & 0.4756 & 0.2262 \\
19 & 63.15 & 31.575 & 0.5236 & 0.2742 \\
20 & 67.59 & 33.795 & 0.5562 & 0.3094 \\
\hline
\end{tabular}


Generally, smallest repeating value in all columns is found and is considered to be ' $A$ '. Lattice parameter is calculated for this value and crystal structure is determined. But sometimes, ' $A$ ' cannot be found for 100 plane, hence lattice parameter ' $a$ ' is calculated at $h k 0$ for all $\sin ^{2} \theta$ values, as was proceeded in the recent case. It is found that the diffraction line having $\sin ^{2} \theta$ value of 0.0914 , gave the most nearest value of ' $a$ ' for 200 plane. This repeating value was also found in the next column of Table 2 , hence it was considered as ' $A$ '. ' $C$ ' was determined by the following relation [8]:

$$
\sin ^{2} \theta-A\left(h^{2}+h k+k^{2}\right)=C l^{2}
$$

The values of $A, 3 A, 4 A$, etc. were subtracted from corresponding $\sin ^{2} \theta$ values to find the remainders $1,4,9,16$, etc., as shown in Table 3 . The value of ' $C$ ' was found to be 0.0011 . The corresponding value of $\sin ^{2} \theta$ is combination of $2 A$ and $C$, hence $h k l$ assigned to this value are 201. Such combinations $(A+C, 2 A+2 C, 3 A+C, 3 A+2 C$, etc. $)$ of $\sin ^{2} \theta$ values were found to assign $h k l$ values to various diffraction lines. These $h k l$ values are listed in the most right column of Table 3 and are shown in Fig. 2. These $h k l$ values confirm that the diffraction pattern belongs to a hexagonal crystal structure. The lattice parameter ' $c$ ' was calculated with the help of Eq. (4) [8]:

Table 2. Values of $\sin ^{2} \theta$ and its multiples (by $\frac{1}{3}, \frac{1}{4}, \frac{1}{7}$ ) to find out $h k l$.

\begin{tabular}{cccccc}
\hline Line & $\sin ^{2} \theta$ & $\frac{\sin ^{2} \theta}{3}$ & $\frac{\sin ^{2} \theta}{4}$ & $\frac{\sin ^{2} \theta}{7}$ & $h k l$ \\
\hline 1 & 0.0401 & 0.0134 & 0.0100 & 0.0057 & \\
2 & 0.0487 & 0.0162 & 0.0122 & 0.0070 & \\
3 & 0.0627 & 0.0209 & 0.0157 & 0.0090 & \\
4 & 0.0683 & 0.0228 & 0.0171 & 0.0098 & \\
5 & 0.0710 & 0.0237 & 0.0177 & 0.0101 & \\
6 & 0.0775 & 0.0258 & 0.0194 & 0.0111 & \\
7 & 0.0862 & 0.0287 & 0.0216 & 0.0123 & \\
8 & 0.0914 & 0.0305 & 0.0229 & 0.0131 & 200 \\
9 & 0.0925 & 0.0308 & 0.0231 & 0.0132 & \\
10 & 0.0981 & 0.0327 & 0.0245 & 0.0140 & \\
11 & 0.1012 & 0.0337 & 0.0253 & 0.0145 & \\
12 & 0.1192 & 0.0397 & 0.0298 & 0.0170 & \\
13 & 0.1317 & 0.0439 & 0.0329 & 0.0188 & \\
14 & 0.1580 & 0.0527 & 0.0395 & 0.0226 & \\
15 & 0.1806 & 0.0602 & 0.0452 & 0.0258 & \\
16 & 0.2058 & 0.0686 & 0.0514 & 0.0294 & \\
17 & 0.2146 & 0.0715 & 0.0537 & 0.0307 & \\
18 & 0.2262 & 0.0754 & 0.0566 & 0.0323 & \\
19 & 0.2742 & 0.0914 & 0.0685 & 0.0392 & \\
20 & 0.3094 & 0.1031 & 0.0773 & 0.0442 & \\
\hline
\end{tabular}




$$
c=\frac{\lambda^{2}}{4 C^{2}}
$$

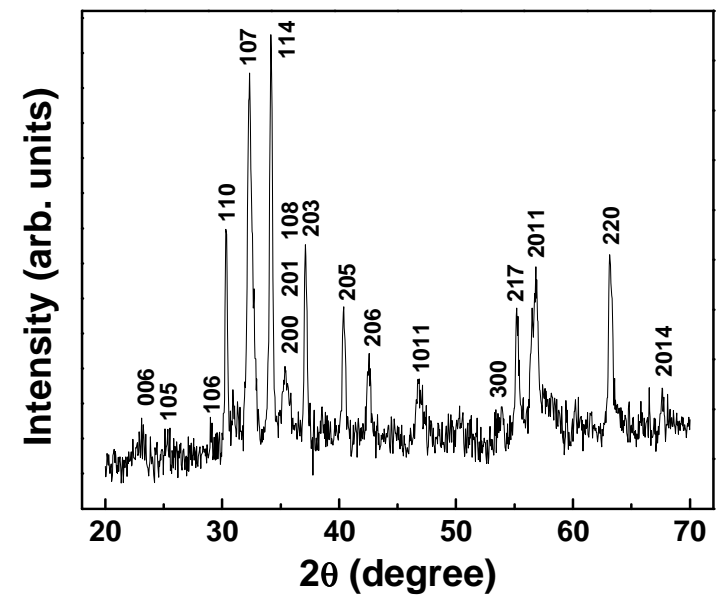

Fig. 2. Indexing of X-ray diffraction pattern.

Table 3. Values of $\sin ^{2} \theta$ and subtracted ones to find out value of $C$.

\begin{tabular}{|c|c|c|c|c|}
\hline Line & $\sin ^{2} \theta$ & $\sin ^{2} \theta-\mathrm{A}$ & $\sin ^{2} \theta-3 \mathrm{~A}$ & $h k l$ \\
\hline 1 & 0.0401 & & & 006 \\
\hline 2 & 0.0487 & & & 105 \\
\hline 3 & 0.0627 & & & 106 \\
\hline 4 & 0.0683 & & & 110 \\
\hline 5 & 0.0710 & & & 008 \\
\hline 6 & 0.0775 & & & 107 \\
\hline 7 & 0.0862 & & & 114 \\
\hline 8 & 0.0914 & 0.0000 & & 200 \\
\hline 9 & 0.0925 & 0.0011 & & 201 \\
\hline 10 & 0.0981 & 0.0067 & & 202 \\
\hline 11 & 0.1012 & 0.0098 & & 203 \\
\hline 12 & 0.1192 & 0.0278 & & 205 \\
\hline 13 & 0.1317 & 0.0403 & & 206 \\
\hline 14 & 0.1580 & 0.0666 & & 1011 \\
\hline 15 & 0.1806 & 0.0892 & & 209 \\
\hline 16 & 0.2058 & 0.1144 & & 300 \\
\hline 17 & 0.2146 & 0.1232 & & 217 \\
\hline 18 & 0.2262 & 0.1348 & & 2011 \\
\hline 19 & 0.2742 & 0.1828 & 0.0000 & 220 \\
\hline 20 & 0.3094 & 0.2180 & 0.0352 & 2014 \\
\hline
\end{tabular}


The same procedure was repeated for indexing the patterns of all the compositions as shown in Fig. 3 and their lattice parameters were determined in the same way. These values are listed in Table 4 . The results show that the lattice parameters ' $a$ ' and ' $c$ ' are increased with increase in $\mathrm{Pb}$ concentration, as shown in Fig. 4. These changes may be due to larger ionic radius of $\mathrm{Pb}^{2+}(12.0 \mathrm{~nm})$ than that of $\mathrm{Sr}^{2+}(11.3 \mathrm{~nm})$ [9]. The $c / a$ ratio was also calculated for all the samples.

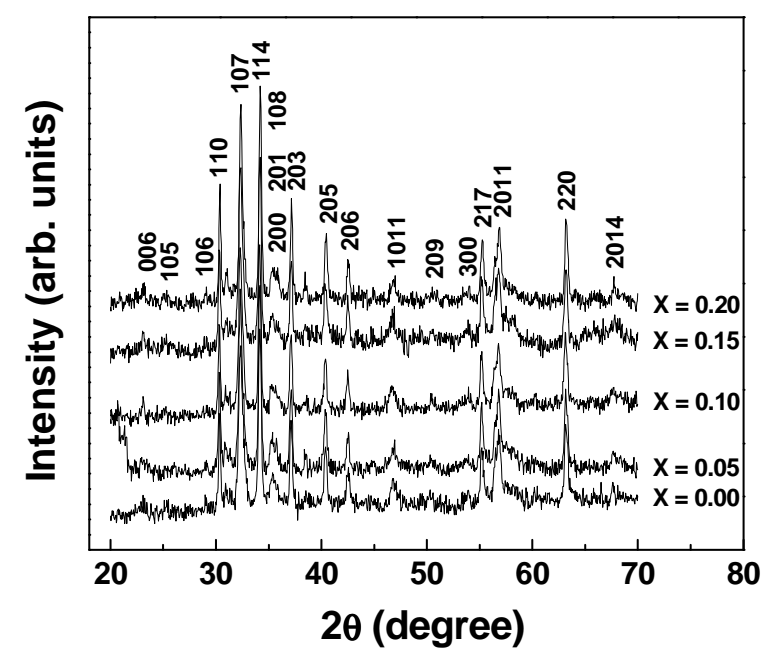

Fig. 3. X-ray diffraction patterns of all the samples

The volume of the unit cell was calculated by the relation as in ref. [13]:

$$
V=\sqrt{3} \times a^{2} \times \frac{c}{2}=0.866 a^{2} c
$$

Unit cell volumes of all the samples are also given in Table 4. Due to increasing trend of lattice parameters ' $a$ ' and ' $c$ ', the volume of the unit cell is also increased with increasing $\mathrm{Pb}$ contents, as reported previously [12].

The crystallite size was measured for peak (114) using Scherrer's formula, given as [8]:

$$
D=\frac{k \lambda}{\beta \cos \theta}
$$

Here, ' $D$ ' is crystallite size, ' $\lambda$ ' is wavelength of incident $\mathrm{X}$-ray, ' $\beta$ ' represents full width half maximum (FWHM) in radians, and ' $\theta$ ' is Bragg angle. ' $k$ ' is a shape factor, having value of 0.94 in the recent case. Crystallite size calculated for various 
compositions is given in Table 4. It is clear that crystallite size is increased with increase in doping ratio, which might be due to larger ionic size of $\mathrm{Pb}^{2+}$ [12].

Although, there was no distinct peak of $\mathrm{Pb}$ in diffraction patterns of $\mathrm{Pb}$-doped compositions, but the increase in lattice parameters, volume and crystallite size proves the presence of $\mathrm{Pb}$. The bulk density of the material was calculated as in ref. [13]:

$$
\rho_{b}=\frac{m}{\pi r^{2} h}
$$

In this relation, ' $m$ ' is mass, ' $r$ ' is radius of the pellet in disk form and ' $h$ ' is height or thickness of the sample. Bulk density for all the materials has been calculated and it is observed that its value is increased with increase of $\mathrm{Pb}$ concentration which is according to the previous results [12]. The X-ray density was determined with the help of following expression [13]:

$$
\rho_{x}=\frac{2 M}{N_{A} V}
$$

where ' $M$ ' is molecular weight of the material and it is multiplied by ' 2 ' because one unit cell contains two molecules of the material. ' $N_{A}$ ' is Avogadro's number and ' $V$ ' is volume of the unit cell, determined by Eq. (50.

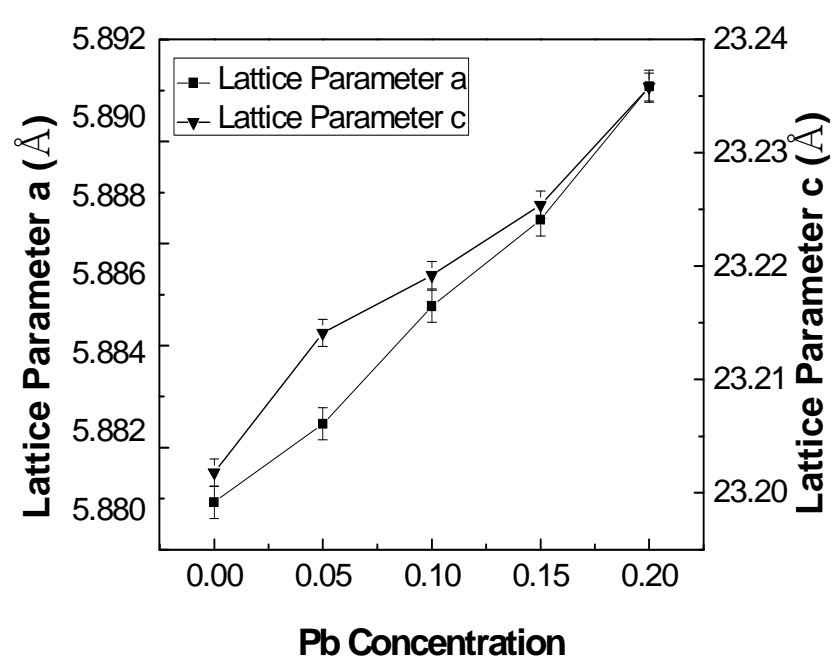

Fig. 4. Effect of $\mathrm{Pb}$ doping on lattice parameters.

The calculated values of X-ray density are tabulated in Table 4. Now, porosity of the material can easily be determined by Eq. (8) [13]: 


$$
P=1-\frac{\rho_{b}}{\rho_{x}}
$$

The calculated values of porosity for all the samples are given in Table 4 .

Table 4. Calculated values of lattice parameters ' $a$ ' and ' $c$ ', $c / a$ ratio, volume of the unit cell $(V)$, crystallite size $(D)$, bulk density of the material $\left(\rho_{b}\right)$, X-ray density $\left(\rho_{x}\right)$ and porosity $(P)$ of the material.

\begin{tabular}{cccccc}
\hline Parameter & $x=0.00$ & $x=0.05$ & $x=0.10$ & $x=0.15$ & $x=0.20$ \\
\hline$a(\AA)$ & 5.8802 & 5.8822 & 5.8852 & 5.8874 & 5.8908 \\
$c(\AA)$ & 23.2018 & 23.2141 & 23.2192 & 23.2254 & 23.2358 \\
$c / a$ & 3.9463 & 3.9463 & 3.9448 & 3.9448 & 3.9448 \\
$V\left(\mathrm{~nm}^{3}\right)$ & 69.4742 & 69.5584 & 69.6446 & 69.7153 & 69.8271 \\
$D(\mathrm{~nm})$ & 29.9270 & 32.1438 & 32.5481 & 33.1472 & 34.7200 \\
$\rho_{b}\left(\mathrm{~g} / \mathrm{cm}^{3}\right)$ & 2.63 & 2.76 & 2.89 & 2.94 & 3.01 \\
$\rho_{x}\left(\mathrm{~g} / \mathrm{cm}^{3}\right)$ & 5.08 & 5.10 & 5.12 & 5.14 & 5.16 \\
$P$ & 0.4823 & 0.4588 & 0.4356 & 0.4280 & 0.4167 \\
\hline
\end{tabular}

\section{Conclusion}

Sr-hexaferrites were prepared by sol-gel auto-ignition technique and were studied for their crystal structure investigation. A complete procedure to determine the crystal structure from X-ray diffraction data has been described and crystal structure of the given material has been found. It was observed that the lattice parameters ' $a$ ' and ' $c$ ' were increased with increase in doping concentration; hence volume of the unit cell was also increased. This was due to large ionic size of $\mathrm{Pb}$ than that of Sr. Crystallite size was increased from 29.93 $\mathrm{nm}$ to $34.72 \mathrm{~nm}$. Bulk density of the material, X-ray density and porosity were calculated for various compositions of $\mathrm{Pb}$-doped $\mathrm{Sr}$ hexaferrites. On increasing bulk and $\mathrm{X}$-ray density values, the porosity decreased from 0.4823 to 0.4167 .

\section{References}

1. S. Hussain, A. Maqsood, A. Ali, and M. Naeem, J. Supercond. Nov. Magn. 24, 1245 (2011). http://dx.doi.org/10.1007/s10948-010-1115-Z

2. A. Drmota, M. Drofenik, and A. Znidarsic, Ceram Int. 38, 973 (2012). http://dx.doi.org/10.1016/j.ceramint.2011.08.018

3. W. Onreabroy, K. Papato, G. Rujijanagul, K. Pengpat, and T. Tunkasiri, Ceram Int. 38S, S415 (2012). http://dx.doi.org/10.1016/j.ceramint.2011.05.023

4. R. Martinez Garcia, V. Bilovol, and L. M. Socolovsky, Physica B 407, 3109 (2011). http://dx.doi.org/10.1016/j.physb.2011.12.038

5. Z. Ullah, S. Atiq, and S. Naseem, J. Alloys Compd. 555, 263 (2013). http://dx.doi.org/10.1016/j.jallcom.2012.12.061 


\section{Indexing the Diffraction Patterns}

6. M. M. Rahman, P. K. Halder, F. Ahmed, T. Hossain, and M. Rahaman, J. Sci. Res. 4 (2), 297 (2012). http://dx.doi.org/10.3329/jsr.v4i2.9752

7. S. Akhter, D. P. Paul, M. A. Hakim, S. Akhter, D. K. Saha, B. Anjuman, and F. Islam, J. Sci. Res. 4 (3), 551 (2012). http://dx.doi.org/10.3329/jsr.v4i3.10798

8. B. D. Cullity, Elements of X-ray Diffraction, 2nd Ed., (Addison-Wesley, Manila, Philippines, 1978) pp. 324-339.

9. C. B. Carter and M. G. Norton, Ceramic Materials/Science and Engineering (Springer, New York, 2007) pp. 101-108.

10. C. M. Fang, F. Kools, R. Metselaar, G. de With, and R. A. de Groot, J. Phys.: Condens. Matter 15, 6229 (2003). http://dx.doi.org/10.1088/0953-8984/15/36/311

11. M. J. Iqbal, M. N. Ashiq, and P. H. Gomez, J. Alloys Compd. 478, 736 (2009). http://dx.doi.org/10.1016/j.jallcom.2008.11.136

12. S. Hussain, and A. Maqsood, J. Alloys Compd. 466, 293 (2008). http://dx.doi.org/10.1016/j.jallcom.2007.11.074

13. S. Hussain and A. Maqsood, J. Magn. Magn. Mater. 316, 73 (2007). http://dx.doi.org/10.1016/j.jmmm.2007.03.206 